\title{
The Cost of Technical Trading Rules in the Forex Market: A Utility-based Evaluation
}

\section{Hans Dewachter and Marco Lyrio}

\begin{tabular}{|l|l|}
\hline ERIM REPORT SERIES RESEARCH IN MANAGEMENT \\
\hline ERIM Report Series reference number & ERS-2003-052-F\&A \\
\hline Publication status / version & May 2003 \\
\hline Number of pages & 31 \\
\hline Email address corresponding author & hdewachter@ffk.eur.nl \\
\hline Address & Erasmus Research Institute of Management (ERIM) \\
& Rotterdam School of Management / Faculteit Bedrijfsunde \\
& Rotterdam School of Economics / Faculteit Economische \\
& Wetenschappen \\
& Erasmus Universiteit Rotterdam \\
& PoBox 1738 \\
& 3000 DR Rotterdam, The Netherlands \\
& Phone: \# 31-(0) 10-408 1182 \\
& Fax: \# 31-(0) 10-408 9640 \\
& Email: info@erim.eur.nl \\
& Internet: www.erim.eur.nl \\
\hline
\end{tabular}

Bibliographic data and classifications of all the ERIM reports are also available on the ERIM website: www.erim.eur.nl 


\title{
ERASMUS RESEARCH INSTITUTE OF MANAGEMENT
}

\author{
REPORT SERIES
}

RESEARCH IN MANAGEMENT

\begin{tabular}{|c|c|c|}
\hline \multicolumn{3}{|c|}{ BIBLIOGRAPHIC DATA AND CLASSIFICATIONS } \\
\hline Abstract & \multicolumn{2}{|c|}{$\begin{array}{l}\text { We compute the opportunity cost for rational risk averse agents of using technical trading rules in } \\
\text { the foreign exchange rate market. Our purpose is to investigate whether these rules can be } \\
\text { interpreted as near-rational investment strategies for rational investors. We analyze four di.erent } \\
\text { exchange rates and find that the opportunity cost of using chartist rules tends to be prohibitively } \\
\text { high. We also present a method to decompose this opportunity cost into parts related to investor's } \\
\text { irrationality and misallocation of wealth. The results show that irrationality of chartist beliefs is an } \\
\text { important component of the total opportunity cost of using technical trading rules. }\end{array}$} \\
\hline \multirow{4}{*}{$\begin{array}{l}\text { Library of Congress } \\
\text { Classification } \\
\text { (LCC) }\end{array}$} & $5001-6182$ & Business \\
\hline & $5601-5689$ & Accountancy, Bookkeeping \\
\hline & $4001-4280.7$ & Finance Management, Business Finance, Corporation Finance \\
\hline & HG 4638 & Technical analysis securities \\
\hline \multirow{5}{*}{$\begin{array}{l}\text { Journal of Economic } \\
\text { Literature } \\
\text { (JEL) }\end{array}$} & M & Business Administration and Business Economics \\
\hline & M 41 & Accounting \\
\hline & G 3 & Corporate Finance and Governance \\
\hline & F 31 & Foreign Exchange \\
\hline & G 15 & International Financial Markets \\
\hline \multirow{4}{*}{$\begin{array}{l}\text { European Business Schools } \\
\text { Library Group } \\
\text { (EBSLG) }\end{array}$} & $85 \mathrm{~A}$ & Business General \\
\hline & $225 \mathrm{~A}$ & Accounting General \\
\hline & $220 \mathrm{~A}$ & Financial Management \\
\hline & $220 \mathrm{~T}$ & Quantitative methods for financial methods \\
\hline \multicolumn{3}{|c|}{ Gemeenschappelijke Onderwerpsontsluiting (GOO) } \\
\hline \multirow[t]{4}{*}{ Classification GOO } & 85.00 & Bedrijfskunde, Organisatiekunde: algemeen \\
\hline & 85.25 & Accounting \\
\hline & 85.30 & Financieel management, financiering \\
\hline & 85.33 & Beleggingen \\
\hline \multirow[t]{3}{*}{ Keywords GOO } & \multicolumn{2}{|c|}{ Bedrijfskunde / Bedrijfseconomie } \\
\hline & \multicolumn{2}{|c|}{ Accountancy, financieel management, bedrijfsfinanciering, besliskunde } \\
\hline & \multicolumn{2}{|c|}{ Effectenhandel, Beleggingen, wisselkoersen, Rationaliteit } \\
\hline Free keywords & \multicolumn{2}{|c|}{ technical trading rule, exchange rate } \\
\hline
\end{tabular}




\title{
The Cost of Technical Trading Rules in the Forex Market: A Utility-based Evaluation
}

\author{
Hans Dewachter ${ }^{a, b *}$ and Marco Lyrio ${ }^{a}$ \\ ${ }^{a}$ CES, Catholic University of Leuven \\ ${ }^{b}$ RIFM and ERIM, Erasmus University Rotterdam
}

May 2003

\begin{abstract}
We compute the opportunity cost for rational risk averse agents of using technical trading rules in the foreign exchange rate market. Our purpose is to investigate whether these rules can be interpreted as near-rational investment strategies for rational investors. We analyze four different exchange rates and find that the opportunity cost of using chartist rules tends to be prohibitively high. We also present a method to decompose this opportunity cost into parts related to investor's irrationality and misallocation of wealth. The results show that irrationality of chartist beliefs is an important component of the total opportunity cost of using technical trading rules.
\end{abstract}

Keywords: technical trading rule, exchange rate.

J.E.L.: F31, G15.

\footnotetext{
${ }^{*}$ Corresponding author. Address: Center for Economic Studies, Catholic University of Leuven, Naamsestraat 69, 3000 Leuven, Belgium. Tel: (+)32(0)16-326859, e-mail: hans.dewachter@econ.kuleuven.ac.be. We are grateful for financial support from the FWO-Vlaanderen (Project No.:G.0332.01). The latest version of this paper can be downloaded from http://www.econ.kuleuven.ac.be/ew/academic/intecon/Dewachter/default.htm. The authors are responsible for remaining errors.
} 


\section{Introduction}

Despite the numerous studies reporting the pervasive use of technical trading rules and their profitability, ${ }^{1}$ there is still a considerable amount of scepticism in the academic literature regarding their true value. Critics of chartist rules often point to the seemingly suboptimal nature of the portfolio composition implied by these rules (e.g. Skouras, 2001). After all, investment strategies based on technical trading rules (i) restrict the information set to a narrow group of pre-defined information variables, (ii) assume a positive relation of the signal with future expected excess returns ${ }^{2}$, and (iii) imply a bang-bang type of investment strategy, i.e. a strategy where all wealth is invested either short or long. Each of these assumptions goes against the standard rational investor paradigm. The first two assumptions possibly go against the rationality of expectations formation, while the third is in general at odds with the assumption of risk aversion.

In this paper, we assess the value of technical trading rules for rational risk averse investors. The main motivation being that even if technical trading rules turn out to be suboptimal rules, the observed practice of using these rules could still be near rational for a large class of risk averse agents. More specifically, if the cost (as measured, for instance, by certainty equivalents) for risk averse agents of using technical trading rules is low, one may argue that following these (irrational) rules of thumb may come close to the optimal trading strategy and could, therefore, be rationalized in terms of information cost type of arguments.

The opportunity cost associated with the use of technical trading rules for risk averse agents can be decomposed in two components: the first component relates to the potential error in the assumed relation between the chartist signal and the expected future return (expectational error); the second component originates from the suboptimality of the investment strategy (allocation error). We present a simple method to compute each of these components. The method involves the introduction of a hypothetical risk neutral agent. Risk neutral liquidity constrained agents have in common with technical traders that investment strategies will be typically bang-bang solutions, i.e. either invest all wealth in the long or in the short side. In fact, as argued by Skouras (2001), as long as the chartist signal is one-to-one with the expected future excess return, chartist trading strategies are equivalent to those of a rational risk neutral liquidity constrained agent. In this case, chartist rules are, therefore, also rational. Differences in the trading positions of a risk neutral and a technical trader isolate, therefore, the costs associated with expectational errors in the relation between the technical trading signal and the expected return. The second cost component -associated with the misallocation of wealth- can be recovered by contrasting the portfolio positions of risk averse and risk neutral agents. Since both agents have identical expectations, the difference in their trading positions can be linked to the costs of risk averse agents investing according to bangbang investment strategies. Combining these cost components results in a total opportunity

\footnotetext{
${ }^{1}$ See, among others, Gençay (1999); LeBaron (1992, 1999, 2000); Neely et al (1997); and Taylor (1980).

${ }^{2}$ We assume here a standardized rule where a positive (negative) technical trading signal corresponds to a long (short) investment position.
} 
cost for a rational risk averse agent of using technical trading rules. We use this technique to identify possible classes of risk averse agents for which these opportunity costs are limited. In this case, one could perhaps rationalize the use of trading rules in terms of near-rational behavior.

Computing the costs of chartist trading rules implies both the identification of technical trading signals and the design of a statistical model to relate the conditional moments of the excess returns to the technical trading signal. In this paper, we restrict the analysis to the class of moving average signals, or rules. We select this class as it constitutes the most widely used class of technical trading rules in the foreign exchange market. These rules have also been shown to be robust in their profit generating capacities. We also opt for a relatively simple model relating return moments to the trading signal. While more advanced techniques such as the nonparametric regression technique of Brandt (1999), or nonlinear models such as neural nets (Gençay, 1999) or Markov switching models (e.g. Dewachter, 2001) could be used, we try to strike a balance between generality and computational costs. We, therefore, use a regression approach to estimate possible time-varying parameters of a Taylor expansion of the relation between return moments and trading signals. This approach is sufficiently flexible to allow for nonlinearities in the signal-return moment relation while at the same time it is computationally tractable so as to allow for continuous updating of the parameters.

The remainder of the paper is organized in three main sections. In section 2 , we discuss the proposed decomposition of the costs associated with the use of technical trading rules. The empirical results are presented in section 3 . In this section, we first analyze the statistical models relating trading signals to return moments. We do find evidence of a nonlinear relation both for the expected return and for the conditional variance. Using these models to construct the optimal portfolio rule for classes of risk averse agents, we subsequently analyze the value of technical trading signals and the costs associated with following technical trading rule strategies. We summarize the main findings of the paper in the concluding section.

\section{The opportunity cost of technical trading rules}

Technical trading rules are typically rules of thumb that relate a certain information variable, the technical trading signal, to a trading position. Denoting the time $t$ technical trading signal by $z_{t}$, the technical trading rule specifies a mapping from the signal $z_{t}$ to an advised trading position $\omega_{C H}\left(z_{t}\right)$. A typical feature is the discontinuity in the mapping $\omega_{C H}\left(z_{t}\right)$. We assume that the trading signal has been standardized such that the trading rule, i.e. the mapping from the signal to the trading position, can be described by:

$$
\omega_{C H}\left(z_{t}\right)=\left\{\begin{array}{r}
b \text { if } z_{t}>0 \\
0 \text { if } z_{t}=0 \\
-b \text { if } z_{t}<0
\end{array}\right.
$$


where $b>0$ denotes the liquidity constraint faced by the chartist trader. ${ }^{3}$

Obviously, the optimal portfolio composition in general differs from the one implied by the technical trading rule strategy. As noted by Skouras (2001), utility-based optimal trading rules typically depend on various factors, including the risk aversion and rational expectations about the conditional return distribution. For a rational, liquidity constrained, risk averse agent, the optimal trading strategy can be written as the solution to the following standard portfolio allocation problem:

$$
\begin{aligned}
& \max _{\omega} E_{t}\left[U\left(W_{t+1}\right)\right] \\
& \text { s.t. } \\
& \Delta W_{t+1}=W_{t}\left(1+r_{f}+\omega X_{t+1}\right) \\
& \omega \in[-b, b]
\end{aligned}
$$

where $r_{f}$ denotes the risk-free interest rate, and $X_{t+1}$ the speculative return above the riskless rate obtained from investing in the risky asset. Note, moreover, that we implicitly assume that the expectations are adapted to the information set used to construct the technical trading signal $z_{t}$. Formally, we assume that $E_{t}\left[X_{t+1}\right]=E\left[X_{t+1} \mid z_{t}\right]$. By assuming a second order Taylor expansion, we recast the above problem into a standard mean variance problem with optimal portfolio allocation:

$$
\omega_{R A}^{*}=\frac{E_{t}\left[X_{t+1}-r_{f}\right]}{\gamma \operatorname{Var}_{t}\left(X_{t+1}\right)}
$$

where $\gamma$ denotes the investor's level of relative risk aversion. Since typical technical trading rules simply specify positions (long or short), only under very restrictive circumstances will these technical trading rules emerge as optimal trading rules. This is only possible, as mentioned by Skouras (2001), in the case of risk neutrality combined with liquidity constraints. In this case, the typical optimal portfolio is a bang-bang solution and the investment position is determined based only on the sign of the expected return. More formally, for a risk neutral investor $(\gamma=0)$, the optimal trading rule is given by:

$$
\omega_{R N}^{*}=\left\{\begin{aligned}
b & \text { if } E_{t}\left[X_{t+1}\right]>0 \\
0 & \text { if } E_{t}\left[X_{t+1}\right]=0 \\
-b & \text { if } E_{t}\left[X_{t+1}\right]<0
\end{aligned}\right.
$$

A small remark to be made to the above mentioned Skouras (2001) result is, however, that even this bang-bang solution under risk neutrality only collapses to the standard technical trading rule if the relation between the expected return and the chartist signal is one-to-one. Making this additional assumption we have that the optimal risk neutral trading rule under liquidity constraints collapses to the chartist rule. More formally, only if the equivalences below hold

\footnotetext{
${ }^{3}$ Although not considered here, trading rules can also include bands of inaction.
} 
will the optimal rule be equivalent to the standard chartist trading rule $\left(\omega_{R N}^{*}=\omega_{C H}\right)$ as presented in eq. (1):

$$
\begin{aligned}
& E_{t}\left[X_{t+1}\right]>0 \Leftrightarrow z_{t}>0, \\
& E_{t}\left[X_{t+1}\right]=0 \Leftrightarrow z_{t}=0, \text { and } \\
& E_{t}\left[X_{t+1}\right]<0 \Leftrightarrow z_{t}<0 .
\end{aligned}
$$

Technical trading rules are, therefore, not necessarily irrational trading strategies. To the extent that the information variable $z_{t}$ corresponds one-to-one with the rationally expected direction of the return, the strategy is optimal for risk neutral agents. Moreover, given the continuity of the portfolio positions in $\gamma$, technical trading strategies could also function as near-rational trading rules for a specific subclass of risk averse agents, i.e. for $\gamma^{\prime} s$ close to zero. If the level of relative risk aversion is relatively high, so that optimal allocation differs substantially from the risk neutral case, or if the chartist trading signal is not one-to-one with rational expected returns, could the opportunity cost of following a technical trading, $\Lambda$, become prohibitively high. This cost can be quantified as the following certainty equivalent:

$$
\Lambda(z)=\left(\omega_{R A}^{*}-\omega_{C H}\right) E_{t}\left[X_{t+1}-r\right]-\frac{1}{2} \gamma\left(\omega_{R A}^{* 2}-\omega_{C H}^{2}\right) \operatorname{Var}_{t}\left(X_{t+1}\right) .
$$

The expected cost of following the chartist trading rule $\omega_{C H}$ instead of the optimal strategy can be decomposed in two separate effects. A first effect is due to the possible error in expectations made by chartist beliefs. A second effect relates to the suboptmality of the actual portfolio position. In order to separate these effects, we make use of the optimal trading strategy of the risk neutral agent, $\omega_{R N}{ }^{4}$

$$
\begin{aligned}
& \Lambda(z)=\Lambda_{E X P}(z)+\Lambda_{A L L}(z) \\
& \Lambda_{E X P}(z)=\left(\omega_{R N}^{*}-\omega_{C H}\right) E_{t}\left[X_{t+1}-r_{f}\right] \\
& \Lambda_{A L L}(z)=\left(\omega_{R A}^{*}-\omega_{R N}\right) E_{t}\left[X_{t+1}-r_{f}\right]-\frac{1}{2} \gamma\left(\omega_{R A}^{* 2}-\omega_{C H}^{2}\right) \operatorname{Var}_{t}\left(X_{t+1}\right) .
\end{aligned}
$$

By construction, both cost components are nonnegative and have a clear interpretation in terms of percentage certainty equivalents. The first term, $\Lambda_{E X P}(z)$, models the loss due to the possible differences between the technical and rational expectations. To the extent that the chartists beliefs are inconsistent with the rationally expected sign of the future returns, following chartist trading rules results in a loss in expected terms. Also, if chartist beliefs with respect to the direction are consistent with rational expectation forecasts of future returns, i.e. the equivalence between $z$ and $E[X]$ holds, this expectations term drops out as risk neutral and chartist trading strategies become the same, $\omega_{C H}=\omega_{R N}$. The second cost component, $\Lambda_{A L L}(z)$, originates from the possible suboptimality of wealth allocation of the technical trading rule. Since technical trading rules advice a bang-bang wealth allocation, i.e. either

\footnotetext{
${ }^{4}$ Adding and subtracting $\omega_{R N}$ in the first term on the right-hand side and noting that independent of $z$, $\omega_{R N}^{2}=\omega_{C H}^{2}$ almost surely, we obtain the proposed decomposition.
} 
full long or short position -depending on the sign of $z$-, technical trading rules neglect the riskiness of the trading position. Risk averse agents obviously take this into account in their trading strategies. The cost to a rational risk averse agent of following the technical trading rule can thus be computed in terms of the differences in the certainty equivalents. This cost, as stated above, can be decomposed into a cost due to the irrationality in expectation formation of the technical trading rule and due to the suboptimality of the wealth allocation. Finally, averaging over the frequency of occurrence of each trading signal, one obtains the unconditional certainty equivalence costs as well as its decomposition.

\section{Empirical analysis}

\subsection{Data and technical trading rules}

The empirical analysis is performed for a set of technical trading rules applied to the exchange rates of four currencies against the U.S. dollar: the German mark, the British pound, the Japanese yen, and the Swiss franc. Exchange rates are expressed in the standard way as the price in the domestic currency of one U.S. dollar, considered here as the foreign currency. We use daily data for the above spot exchange rates obtained from Datastream for the period January 1, 1973 to March 25, 2003, yielding a total of 7886 exchange rate returns.

The type of a trading rule depends on the way the trading signal is computed. In this paper, we restrict the empirical analysis to the class of moving average trading rules. This is one of the most used types of trading rules since the early seventies and has shown to generate excess profits through time in the foreign exchange market. Furthermore, it is the one that seems to be robust also in out-of-sample analysis (see, for instance, Neely et al., 1997). Due to its widespread use, this choice also aims at reducing possible selection bias with respect to the chosen class of trading rules. The technical trading signal $z_{t}$ for this class of rules is constructed as the difference between a short and a long moving average window of past exchange rate returns:

$$
z_{t}=\frac{1}{S} \sum_{j=0}^{S-1} \Delta e_{t-j}-\frac{1}{L} \sum_{j=0}^{L-1} \Delta e_{t-j},
$$

where $e_{t}$ denotes the natural logarithm of the exchange rate at time $t$, and $S(L)$ denotes the size or number of observations of the short (long) window of the moving average signal. $\Delta e_{t-j}=e_{t}-e_{t-1}$ expresses the exchange rate return at time $t$. The investment position at each point in time is then determined based on the sign of $z_{t}$, as expressed in eq. (1). We consider three types of trading signals (or rules) depending on the number of days incorporated in the short $(S)$ and long $(L)$ window of the moving average rule. The following trading rules are used. Rule 1: $S=10, L=50$; Rule 2: $S=20, L=100$; and Rule 3: $S=40, L=200$. Due to the backward-looking nature of the moving average signal, the effective number of data points in the sample of each trading rule depends on the size of the long window used to compute the trading signal.

Finally, in the computation of the return from investing in the exchange rate market, we 
disregard the interest rate differential between the countries. ${ }^{5}$ Besides the fact that these data are not readily available, LeBaron (1999) shows that the exclusion of the interest rate differential is unimportant for trading rule results. We also adopt an arbitrary value for the risk free interest rate equal to zero.

Table 1 presents the standard result found in the literature that investing according to technical trading rules generate significant mean excess returns. In our case, in all but one case mean excess returns are statistically significant at the $10 \%$ level, and in eight out of the twelve cases at the $5 \%$ level. Note, however, that the trading rule profits are not homogeneous across positive and negative signals. Typically, trading rules are profitable in one of the two investment positions. For the British pound-U.S. dollar, and for the three rules considered, only a positive signal results in significant excess returns. For the other three exchange rates, the opposite occurs, with one exception where neither signals generate significant excess returns.

\section{Insert Table 1}

\subsection{Least squares prediction models}

Central in the above analysis is the projection of expected future return moments on the technical trading signal $z_{t}$. Naturally, the type of model used to project these moments on the set of chartist signals influences the results regarding the costs of using chartist strategies. In this paper, we try to strike a balance between the generality in the class of functions used to project moments and the computational cost of continuously updating these projections to take into account the "real-time" flow of information. ${ }^{6}$ We, therefore, approximate the mapping between the first two return moments defined as:

$$
\begin{aligned}
& m_{t}(z)=E_{t}\left[X_{t+1}-r_{f}\right] \\
& v_{t}(z)=\operatorname{Var}_{t}\left(X_{t+1}\right)
\end{aligned}
$$

and the information set, or trading signal, at time $t$ in terms of a Taylor expansion around the mean of $z_{t}$. We, furthermore, assume that agents follow the Least Squares (LS) learning principles, i.e. use Ordinary Least Squares (OLS) techniques to estimate and update the forecasting model according to the information set. In practical terms, we use an expanding window regression framework to estimate the parameters of a Taylor expansion:

$$
\begin{aligned}
& m_{t}(z)=Z^{\prime} \beta_{t} \\
& v_{t}(z)=Z^{\prime} \delta_{t}
\end{aligned}
$$

\footnotetext{
${ }^{5}$ The speculative return $X_{t+1}=\Delta e_{t+1}+r_{f}^{*}-r_{f}$, where $r_{f}^{*}$ represents the risk-free return in the foreign country, can then be simplified to $X e_{t+1} \cong \Delta e_{t+1}$.

${ }^{6}$ Note that the most general technique available to optimize the trading position is the one proposed by Brandt (1999). He combines a nonparametric technique with the first order condition for the optimal portfolio composition in order to derive a mapping between the portfolio and the information variable. This approach could be used here as well. Nevertheless, this technique requires a significant computational effort in the continuous updating of the information set. In a previous version of this paper, we have analyzed the optimality of technical trading rules based on the Brandt technique (see Dewachter and Lyrio, 2002). The portfolio allocation obtained there corresponds closely to the ones reported in this paper.
} 
where $Z \in R^{(P+1) \times 1}$ denotes the vector containing the independent variables: $1, z, z^{2}, \ldots, z^{p}$. The parameter vectors $\beta_{t}$ and $\delta_{t}$ are obtained from regressing observed excess returns on the sample of observed signals. We select the optimal order of the Taylor approximation based on the Akaike Information Criterion (AIC). More specifically, we restrict the maximum order of the expansion to 6 and retain the one that minimizes the AIC. The orders of the Taylor approximations are allowed to differ across the mean and variance equations. For the mean a third order expansion is selected most of the time while for the variance it varies from 2 to 6 across the different exchange rates.

In order to save on space, the regression results are not presented here. ${ }^{7}$ The main results are, however, shown in the top panels of Figures 1 to 3 which present the expected mean and variance of excess returns conditioned on the chartist signal $z$ for the trading rules 1 to 3 , respectively. Two types of estimations are presented. The full line represents the estimation results from our model and the dashed line from a nonparametric approach ${ }^{8}$. The histogram of the trading signal is shown in the background. Three comments are to be made with respect to these results. First, in general, we find that the main patterns of our selected models are corroborated by the nonparametric regression technique. This indicates that the orders of the Taylor approximations chosen for each of the regresions in (10) seem appropriate.

\section{Insert Figures 1 to 3}

Second, for a certain range of the trading signal around zero, the regression results are in line with the practice of technical traders, i.e. we observe a one-to-one relation between the trading signal and the expected future excess return (top-left panel). One also observes, however, that this relation is both non-linear and non-monotonic. In fact, for more extreme signals, both in size and in frequency of occurrence, this relation becomes inverted giving rise to a contrarian strategy. This can be observed both in the parametric and nonparametric regression results.

Finally, we find that the trading signal contains relevant information concerning future volatility. A feature that, to the best of our knowledge has not been reported in the literature. In line with the standard generalized autoregressive conditional heteroskedasticity (GARCH) literature, we see that the trading signals are correlated with future volatility, implying some predictability of $z$ with respect to $v_{t}$. Also in line with the GARCH literature, we observe a generally symmetric relation between the trading signal and the variance.

In summary, the chartist signal contains significant information with respect to the future evolution of the exchange rate. Nevertheless, the information in the signal does not fully conform with the widely held beliefs of technical traders. Most importantly, the relation between the trading signal and the rationally expected future returns is non-linear and nonmonotonic.

\footnotetext{
${ }^{7}$ All the results are, howeve, available upon request.

${ }^{8}$ For more details, see Dewachter and Lyrio (2002).
} 


\subsection{Empirical evaluation of costs of technical trading rules}

In this section we assess the value of the above mentioned technical trading rules for rational risk averse investors. We consider different types of investors according to their level of relative risk aversion $(\gamma)$. We use as benchmarks four levels of risk aversion $(\gamma=1,5,10,20)$, ranging from a relatively aggressive investor to a very risk averse agent. In this way we cover the range of values commonly found in both the macroeconomic and finance literature regarding the empirically observed levels of risk aversion. As mentioned before, we assume that a second order Taylor expansion of the investor's utility function is sufficient to approximate the true utility function. This allows us to express the value of trading rules in terms of certainty equivalents. Finally, we also introduce symmetric liquidity constraints by stipulating that an agent can only invest his own wealth. The agent is, therefore, not allowed to borrow for speculative purposes. Formally this implies that $b=1$ in eq. (1).

We assess the value of the technical trading rules from two perspectives. First, we perform an in-sample evaluation of the expected certainty equivalent of each of the technical trading rules. Second, based on an out-of-sample analysis, we compute the effective certainty equivalent of an agent using a technical trading signal. In both cases, we decompose the opportunity cost for an agent who deviates from the fully rational investment strategy in favor of the technical trading rule strategy. This decomposition identifies a cost related to irrationality, or expectational cost, and another related to the misallocation of wealth.

\subsubsection{In-sample analysis}

The in-sample analysis is based on the full sample regression results of eq. (10), which models the first two exchange rate return moments. We implicitly assume stationarity of the exchange rate changes and hence stationarity of the distribution of the trading signal $z$. Integrating out the trading signal $z$, we obtain the unconditional certainty equivalent of a risk averse investor $\left(c e q_{R A}\right)$ for each of the technical trading rules or investment strategies:

$$
c e q_{R A}=\frac{1}{T} \sum_{t=1}^{T}\left[\omega_{R A}^{*}\left(z_{t}\right) m_{T}\left(z_{t}\right)-\frac{1}{2} \gamma \omega_{R A}^{* 2}\left(z_{t}\right) v_{T}\left(z_{t}\right)\right]
$$

We also compute the opportunity cost components of following a technical trading rule, i.e. the expectational and allocational costs $\left(\Lambda_{E X P}\right.$ and $\left.\Lambda_{A L L}\right)$ :

$$
\begin{aligned}
& \Lambda=\Lambda_{E X P}+\Lambda_{A L L} \\
& \Lambda_{E X P}=\frac{1}{T} \sum_{t=1}^{T}\left(\omega_{R N}^{*}\left(z_{t}\right)-\omega_{C H}\left(z_{t}\right)\right) m_{T}\left(z_{t}\right)-\frac{1}{2} \gamma \omega_{R A}^{* 2}\left(z_{t}\right) v_{T}\left(z_{t}\right) \\
& \Lambda_{A L L}=\frac{1}{T} \sum_{t=1}^{T}\left(\omega_{R A}^{*}\left(z_{t}\right)-\omega_{R N}^{*}\left(z_{t}\right)\right) m_{T}\left(z_{t}\right)-\frac{1}{2} \gamma\left(\omega_{R A}^{* 2}\left(z_{t}\right)-\omega_{C H}^{2}\left(z_{t}\right)\right) v_{T}\left(z_{t}\right)
\end{aligned}
$$


The optimal portfolio strategy is derived using the final regression results, $\beta_{T}$ and $\delta_{T}$, and is given by the standard mean-variance optimal portfolio, conditioned on the signal $z$ :

$$
\omega_{R A}^{*}\left(z_{t}\right)=\frac{m_{T}\left(z_{t}\right)}{\gamma v_{T}\left(z_{t}\right)}=\frac{Z_{t}^{\prime} \beta_{T}}{\gamma Z_{t}^{\prime} \delta_{T}} .
$$

The four bottom panels of Figures 1 to 3 depict the optimal portfolio composition in function of the observed trading signal $z$. The dashed line shows the unrestricted optimal portfolio, while the full line shows the liquidity constrained optimal portfolio. The histogram of the chartist trading signal is shown in the background. Note that the optimal portfolio deviates significantly from the chartist rule, or bang-bang strategy, adopted by technical traders. For weak absolute trading signals, the optimal portfolio is typically less agressive than the chartist solution (eq.1). These are denoted allocation differences or errors. The optimal rule is also clearly non-linearly related to the trading signal. While for weak signals there seems to be a trend following strategy, i.e. go long when $z>0$ and go short when $z<0$, for strong positive or negative signals the optimal trading strategy tends to become contrarian, i.e. go short if $z>>0$ and long if $z<<0$.

Tables 2 to 4 present the estimated certainty equivalent of the optimal trading strategy and the cost decomposition $\left(\Lambda=\Lambda_{E X P}+\Lambda_{A L L}\right)$ associated with the use of the technical trading rules 1 to 3 , respectively. We can derive a number of observation from these results. First, the chartist signal is, in general, valuable to a rational risk averse agent (see positive $\left.c e q_{R A}\right)$. Overall, certainty equivalents are in between $0.2 \%$ and $6.5 \%$ per year, being higher for more agressive investors. Therefore, specially for agents with relatively low levels of risk aversion, technical trading signals contain, ex post, some value. Nevertheless, this does not imply that rational risk averse agents should turn to technical trading strategies. Although technical trading strategies generate positive certainty equivalents, the cost of replacing optimal investment strategies by technical trading strategies $(\Lambda)$ is still surprisingly high. This cost ranges from $12 \%$ for extreme risk aversion investors to $0.6 \%$ for the very agressive ones.

\section{Insert Tables 2 to 4}

Second, one observes that for low levels of risk aversion $(\gamma=1,5)$, expectational costs constitute the main component of the total opportunity cost of using a certain technical trading rule. For high levels of risk aversion, allocational inefficiencies dominate this opportunity cost, becoming prohibitively large. Figure 4 illustrates this cost decomposition for the DEM/USA exchange rate applying Rule 1 (the values are taken from the last three lines of the top panel in Table 2). Agressive investors (low $\gamma$ ) using chartist rules are then mainly concerned about possible expectational errors, or errors in their judgement regarding the sign of the expected exchange rate return. Most part of the opportunity cost for conservative investors (high $\gamma$ ) making use of technical rules derive from the allocation of wealth in a non-optimized way, i.e. using a bang-bang strategy. Overall, expectational costs range from $0.6 \%$ to $2 \%$ per year. As these numbers constitute a lower bound to the total opportunity cost of using technical rules, one might already conclude that these costs are, in fact, substantial. Even if the above 
costs were considered as reasonable, the allocation costs tend to increase significantly with the increase in the level of risk aversion.

In summary, although chartist signals contain relevant and valuable information to rational risk averse investors, technical trading rules are not an efficient or near-efficient way to incorporate this information. Technical trading rules fail to map accurately signals into trading positions both due to irrational expectations and allocational inefficiencies.

\section{Insert Figure 4}

\subsubsection{Out-of-sample analysis}

In-sample measures of certainty equivalents only represent an accurate value of a specific trading rule if the parameter estimates of the models for the expected return and variance of the excess exchange rate return (eq. (10)) do not vary through time. We verify, however, that these estimates are, in fact, significantly different depending on the size of the sample used. ${ }^{9}$ In this section, therefore, we analyze the investment of a rational risk averse agent in real time and compute two types of measures for the certainty equivalent. One is based on the agent's expectations regarding the exchange rate mean and variance. The other is based on the sample realizations of the mean and variance.

The first variant of the out-of-sample test allows us to analyze to what extent the agent would have expected to have a profitable trading strategy (in terms of certainty equivalents) in real time. We adapt the agent's expectations to the real time information set by computing expanding window regressions up to time $t$ and constructing based on the models presented in eq. (10) the expected return and variance of excess exchange rate returns. In other words, the certainty equivalent is evaluated using the agents beliefs about future expected return and volatility. Averaging over time then gives the average value of the trading signal $z$ over the sample period. Analogously, we compute the cost of changing the optimal trading strategy for the technical trading rule. Formally, this implies that we change the end of sample estimates $m_{T}\left(z_{t}\right)$ and $v_{T}\left(z_{t}\right)$ used in the previous section by their real time analogues: $m_{t}\left(z_{t}\right)$ and $v_{t}\left(z_{t}\right)$. Based on the sequence of models $m_{t}(z)$ and $v_{t}(z), t=T_{0}, \ldots, T$, we can compute the real time analogues of equations (11) and (12):

$$
\begin{aligned}
& c e q_{R A}=\frac{1}{T} \sum_{t=1}^{T}\left[\omega_{R A}^{*}\left(z_{t}\right) m_{t}\left(z_{t}\right)-\frac{1}{2} \gamma \omega_{R A}^{* 2}\left(z_{t}\right) v_{t}\left(z_{t}\right)\right] \\
& \Lambda=\Lambda_{E X P}+\Lambda_{A L L} \\
& \Lambda_{E X P}=\frac{1}{T} \sum_{t=1}^{T}\left(\omega_{R N}^{*}\left(z_{t}\right)-\omega_{C H}\left(z_{t}\right)\right) m_{t}\left(z_{t}\right)-\frac{1}{2} \gamma \omega_{R A}^{* 2}\left(z_{t}\right) v_{t}\left(z_{t}\right) \\
& \Lambda_{A L L}=\frac{1}{T} \sum_{t=1}^{T}\left(\omega_{R A}^{*}\left(z_{t}\right)-\omega_{R N}^{*}\left(z_{t}\right)\right) m_{t}\left(z_{t}\right)-\frac{1}{2} \gamma\left(\omega_{R A}^{* 2}\left(z_{t}\right)-\omega_{C H}^{2}\left(z_{t}\right)\right) v_{t}\left(z_{t}\right)
\end{aligned}
$$

\footnotetext{
${ }^{9}$ Although we omit the regression results here they are available upon request.
} 
with

$$
\omega_{R A}^{*}\left(z_{t}\right)=\frac{m_{t}\left(z_{t}\right)}{\gamma v_{t}\left(z_{t}\right)}=\frac{Z_{t}^{\prime} \beta_{t}}{\gamma Z_{t}^{\prime} \delta_{t}} .
$$

The results are presented in Tables 5 to 7 for the technical trading rules 1 to 3 , respectively. As expected, the certainty equivalents obtained using this dynamic estimation strategy are in general larger than the ones obtained from the in-sample analysis. This indicates that the expected value from the technical trading signal is not marginal. For a low level of risk aversion, $\gamma=1$, we find certainty equivalents ranging from about $4.5 \%$ up to almost $10 \%$ per year across different exchange rates and trading rules. Clearly, technical trading signals contain some value. Nevertheless, as in the in-sample case, this does not mean that a risk averse agent would follow a chartist strategy. The cost of replacing the optimal trading strategy by a technical trading strategy is relatively large. The cost decomposition follows the same pattern presented in Figure (4).

The expectational cost from following the chartist strategy ranges from $1 \%$ to $4 \%$ across exchange rates and tranding rules. Again, these constitute the lower bounds to the costs of using technical trading rules. Since the allocation costs increase with the level of risk aversion, the total cost of using chartist rules becomes probably prohibitively high.

\section{Insert Tables 5 to 7}

In the second variant of the out-of-sample tests, we do not use the expectations but instead the realized returns to compute the average portfolio returns and variance over time. More specifically, we compute the sample analogue of the expectations $m_{t}\left(z_{t}\right)$ and $v_{t}\left(z_{t}\right)$ by realization, respectively, $X_{t+1}$ and $\left(X_{t+1}-m_{t}\left(z_{t}\right)\right)^{2}$. As such, a real out-of-sample evaluation of the certainty equivalent is obtained. As in the previous case, we adapt the optimal trading strategy of the agent to the real time information set. That is, we use expanding window regressions to obtain the time $t$ functions $m_{t}(z)$ and $v_{t}(z)$. In contrast to the previous case, we only use these expectations to compute the optimal portfolio allocation. Averaging these realizations over time gives the ex post realized certainty equivalents and cost decompositions. Note that in this case one would not necessarily expect a non-negative certainty equivalent for the optimal trading strategy. Only if the implied model actually predicts out of sample the expected excess return and variance accurately, one would expect the certainty equivalent to be positive. The results of this full out-of-sample evaluation are presented in Tables 8 to 10 respectively for the trading rules 1 to 3 .

The main conclusion to be drawn from these tables is that the results presented above are quite robust to an out-of-sample evaluation. Most importantly, we find again that the technical trading signal $z$ is a valuable information variable. For risk averse investors, the certainty equivalent is also always positive with the exception of one case (GBP/USD, Rule 2, Table 9). For low risk averse investors, it reaches a value of $8 \%$ per year.

Nevertheless, the total opportunity cost of using a chartist rule is still substantially high in some cases, being around $10 \%$ per year for high risk averse investors. Only in 3 out of the 48 cases (different rules, exchange rates and levels of risk aversion) considered, we obtained 
a negative opportunity cost (Rule 2, Table 9). For these few cases, one would have benefited more from using a chartist rule instead of the optimized portfolio.

Regarding the expectational costs, except for the two cases where it is negative, it ranges from $0.1 \%$ to $3.5 \%$ per year. As mentioned before, these constitute a lower bound on the costs of using the chartist rule. As before, the total costs increase with the level of risk aversion due to the increase in the allocational costs which become prohibitively high for very risk averse investors. The cost decomposition pattern follows the one presented in Figure 4.

\section{Insert Tables 8 to 10}

Once more, we find that the optimal trading strategy is unlikely to be near equivalent to a chartist trading strategy. While technical trading signals do contain valuable information for a standard risk averse investor, this investor would not likely turn to technical trading strategies because both expectational and allocational costs embedded in this strategy are prohibitively high. To answer the main question of this paper, we conclude that technical trading rules are not near rational equivalents to optimal trading rules.

\section{Conclusions}

The main goal of this paper was to answer the basic question whether or not technical trading rules could be interpreted as near rational investment strategies for a class of risk averse agents. Based on the above analysis, we conclude that they cannot be interpreted in that way.

We find that the irrationality of expectations formation, implicit in the class of moving average rules, generates prohibitively high welfare costs to rational agents. Since these expectational costs are independent of the level of risk aversion, they apply to any kind of rational agent. These costs can, therefore, be seen as a lower bound to the opportunity cost for risk averse agents of using chartist rules. This type of cost alone should prevent investors from using the technical trading signal in order to apply chartist trading strategies. The results hold for the three moving average rules and for each of the exchange rates analyzed in this paper. The results are also robust with respect to the method of calculation of the certainty equivalent. Using both a in-sample and an expanding out-of-sample approach, investor's irrationality seem to be an important component in the opportunity cost of using technical trading rules. 


\section{References}

[1] Brandt, M. (1999), "Estimating Portfolio and Consumption Choice: A Conditional Euler Equations Approach", Journal of Finance 54 (5), 1609-1645.

[2] Dewachter, H. (2001), "Can Markov Switching Models Replicate Chartist Profits in the Foreign Exchange Market", Journal of International Money and Finance 20, 25-41.

[3] Dewachter, H. and M. Lyrio (2002), "The Economic Value of Technical Trading Rules: A Nonparametric Utility-based Approach", CES Discussion Paper 02.03, KULeuven.

[4] Gençay, R. (1999), "Linear, Non-linear and Essential Foreign Exchange Rate Prediction with Simple Technical Trading Rules", Journal of International Economics 47, 91-107.

[5] LeBaron, B. (1992), "Do Moving Average Trading Rule Results Imply Nonlinearities in Foreign Exchange Markets?", Working Paper, Department of Economics, University of Wisconsin-Madison.

[6] LeBaron, B. (1999), "Technical Trading Rule Profitability and Foreign Exchange Intervention", Journal of International Economics 49, 125-143.

[7] LeBaron, B. (2000), "Technical Trading Profitability in Foreign Exchange Markets in the 1990's", Working Paper, July.

[8] Neely, C., Weller, P. and R. Dittmar (1997), "Is Technical Analysis in the Foreign Exchange Market Profitable? A Genetic Programming Approach", Journal of Financial and Quantitative Analysis 32 (4), 405-426.

[9] Silverman, B. (1986), Density Estimation for Statistics and Data Analysis, London: Chapman and Hall.

[10] Skouras, S. (2001), "Financial Returns and Efficiency as Seen by an Artificial Technical Analyst" Journal of Economic Dynamics and Control 25, 213-244.

[11] Taylor, S.J. (1980), "Conjectured Models for Trends in Financial Prices, Tests and Forecasts", Journal of the Royal Statistical Society A, 143, 338-362. 
Table 1: Excess returns for the selected technical trading rules

\begin{tabular}{|c|c|c|c|c|}
\hline & DEM/USD & GBP/USD & JPY/USD & CHF /USD \\
\hline & \multicolumn{4}{|c|}{ Trading rule 1: $S=10, L=50$} \\
\hline Return p.a. $z<0$ & $0.06710^{* *}$ & 0.02365 & $0.07846^{* *}$ & $0.08993^{* *}$ \\
\hline Return p.a. $z>0$ & 0.03917 & $0.05378^{* *}$ & 0.02365 & 0.03317 \\
\hline \multirow[t]{2}{*}{ Return p.a. } & $0.05316^{* *}$ & $0.03870^{* *}$ & $0.04992^{* *}$ & $0.06156^{* *}$ \\
\hline & \multicolumn{4}{|c|}{ Trading rule $2: S=20, L=100$} \\
\hline Return p.a. $z<0$ & $0.06730^{* *}$ & 0.03015 & $0.08763^{* *}$ & $0.06181^{*}$ \\
\hline Return p.a. $z>0$ & 0.03964 & $0.06307^{* *}$ & 0.02928 & 0.00704 \\
\hline \multirow[t]{2}{*}{ Return p.a. } & $0.05338^{* *}$ & $0.04663^{* *}$ & $0.05703^{* *}$ & 0.03416 \\
\hline & \multicolumn{4}{|c|}{ Trading rule $3: S=40, L=200$} \\
\hline Return p.a. $z<0$ & 0.04503 & 0.02736 & $0.06378^{* *}$ & $0.07159^{* *}$ \\
\hline Return p.a. $z>0$ & 0.02311 & $0.05515^{* *}$ & 0.00759 & 0.01336 \\
\hline Return p.a. & $0.03354^{*}$ & $0.04147^{* *}$ & $0.03490^{*}$ & $0.04071^{*}$ \\
\hline
\end{tabular}

Returns are presented in per annum terms by multiplying the daily returns by the number of trading days, taken here to be 262. The entry Return p.a. $z<0$ measures the average return obtained when the signal $\mathrm{z}$ was negative, implying a short position. Analogously, Return p.a. $z<0$ measures the return from the long position based on positive $z$ signal. Under the entry Return, the average return from trading according to the chartist signals is presented.

** and * respectively indicate that the averages are statistically different from zero at the $5 \%$ and $10 \%$ significance level, respectively. 

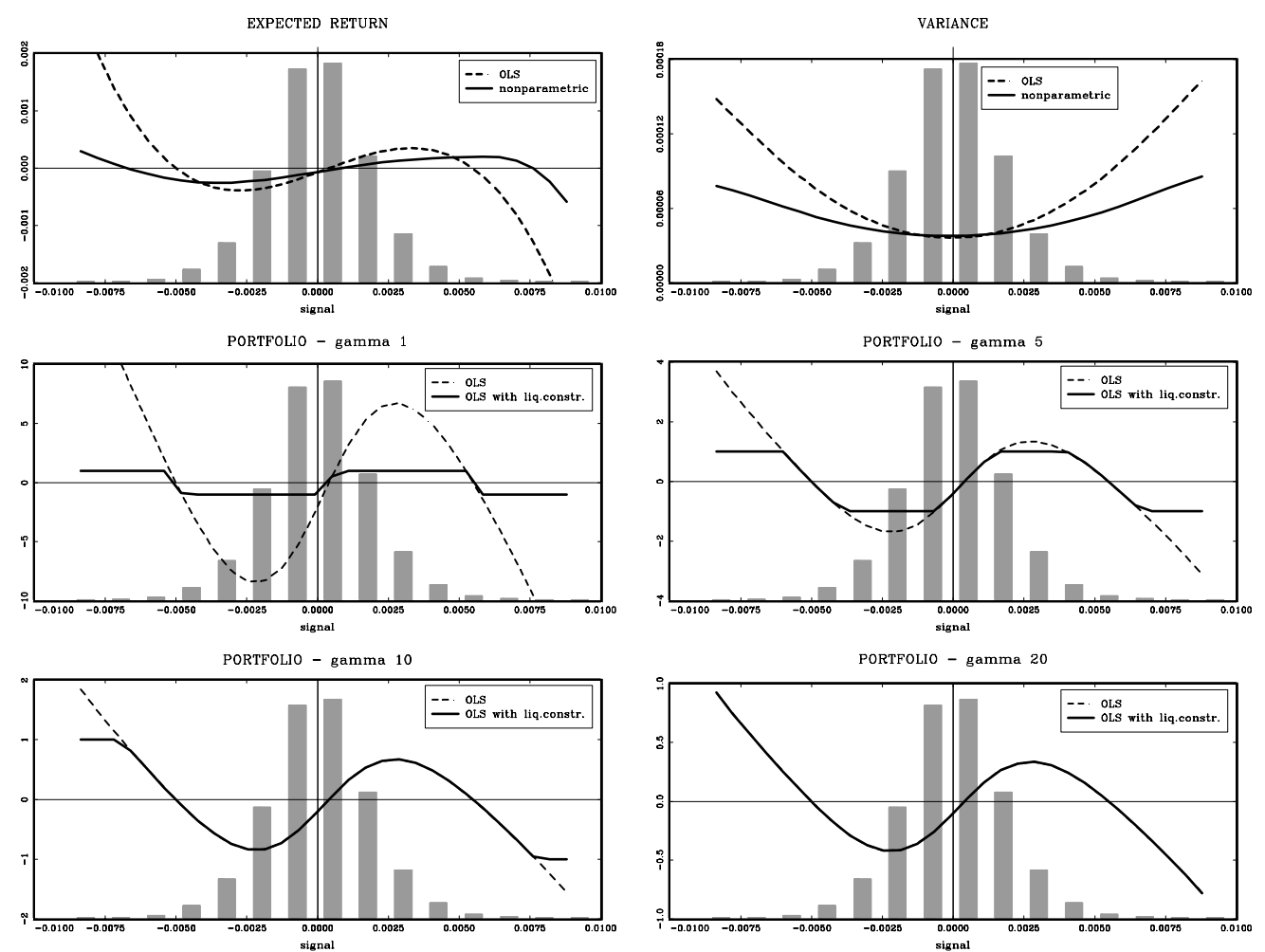

Figure 1: Expected return, expected squared return and portfolio choice - Rule 1 



Figure 2: Expected return, expected squared return and portfolio choice - Rule 2 

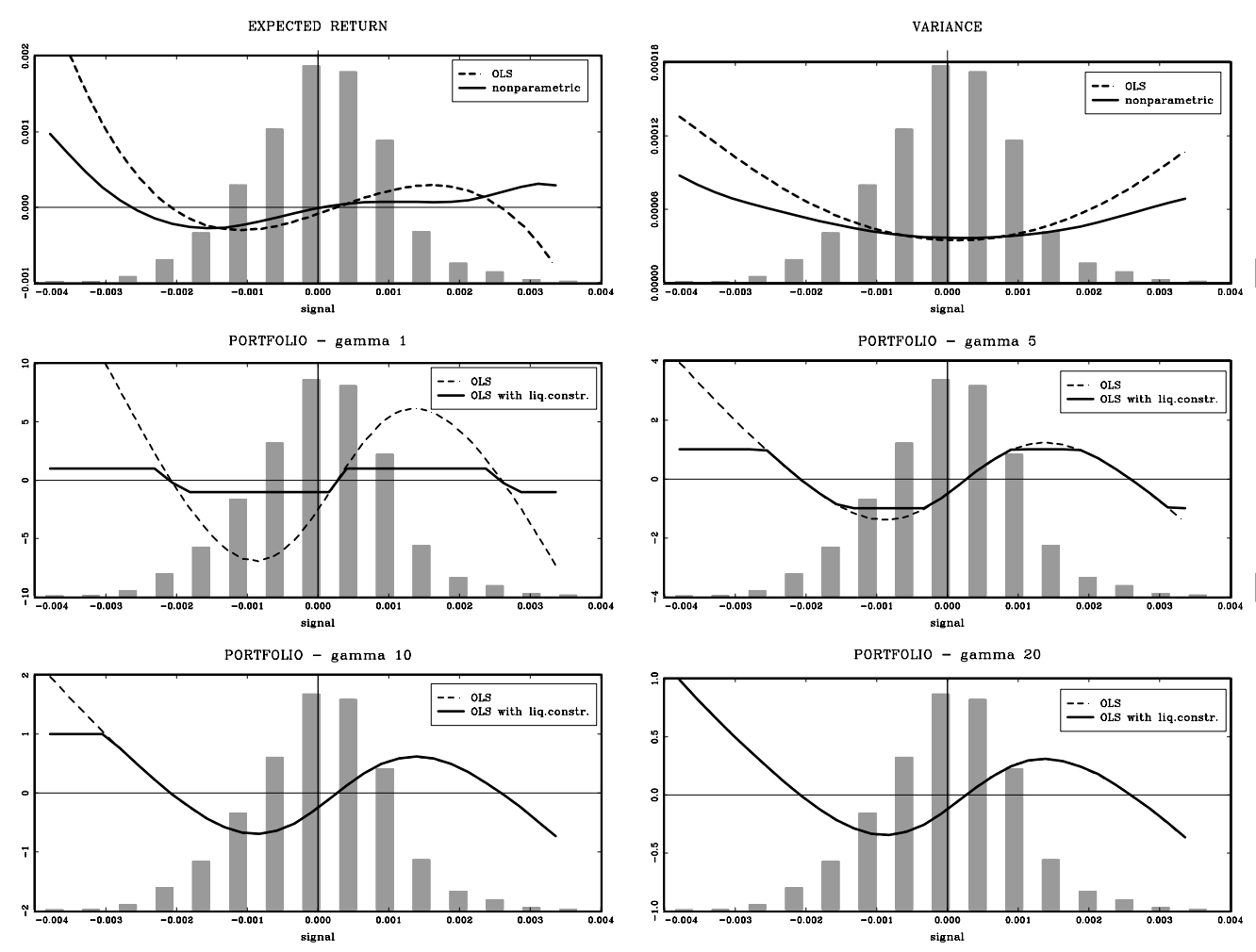

Figure 3: Expected return, expected squared return and portfolio choice - Rule 3

OPPORTUNITY COST DECOMPOSITION



Figure 4: Opportunity cost decomposition. DEM/USA, Rule 1 
Table 2: In-sample analysis of certainty equivalent and cost decomosition of technical trading rules. Rule 1: $\mathrm{S}=\mathbf{1 0}, \mathrm{L}=\mathbf{5 0}$

\begin{tabular}{|c|c|c|c|c|}
\hline & CRRA =1 & CRRA $=5$ & CRRA $=10$ & $\mathrm{CRRA}=20$ \\
\hline & \multicolumn{4}{|c|}{$\mathrm{DEM} / \mathrm{USD}: p_{m}=3, p_{v}=2$} \\
\hline $\operatorname{ceq}_{R A}$ & 0.04872 & 0.03063 & 0.01693 & 0.00855 \\
\hline $\operatorname{ceq}_{R N}$ & 0.04855 & 0.02638 & -0.00133 & -0.05675 \\
\hline $\operatorname{ceq}_{C H}$ & 0.04199 & 0.04872 & -0.00788 & -0.06330 \\
\hline$\Lambda_{E X P}$ & 0.00656 & 0.00656 & 0.00656 & 0.00656 \\
\hline$\Lambda_{A L L}$ & 0.00018 & 0.00425 & 0.01826 & 0.06529 \\
\hline \multirow[t]{2}{*}{$\Lambda$} & 0.00673 & 0.01081 & 0.02481 & 0.07185 \\
\hline & \multicolumn{4}{|c|}{ GBP/USD: $p_{m}=4, p_{v}=6$} \\
\hline$\overline{\operatorname{ceq}_{R A}}$ & 0.03565 & 0.02075 & 0.01120 & 0.00607 \\
\hline $\operatorname{ceq}_{R N}$ & 0.03551 & 0.01727 & -0.00554 & -0.05115 \\
\hline $\operatorname{ceq}_{C H}$ & 0.02687 & 0.00863 & -0.01418 & -0.05979 \\
\hline$\Lambda_{E X P}$ & 0.00864 & 0.00864 & 0.00864 & 0.00864 \\
\hline$\Lambda_{A L L}$ & 0.00014 & 0.00348 & 0.01674 & 0.05722 \\
\hline \multirow[t]{2}{*}{$\Lambda$} & 0.00878 & 0.01212 & 0.02538 & 0.06586 \\
\hline & \multicolumn{4}{|c|}{ JPY /USD: $p_{m}=3, p_{v}=4$} \\
\hline $\operatorname{ceq}_{R A}$ & 0.05550 & 0.03739 & 0.02413 & 0.01254 \\
\hline $\operatorname{ceq}_{R N}$ & 0.05533 & 0.03274 & 0.00450 & -0.05196 \\
\hline $\operatorname{ceq}_{C H}$ & 0.04312 & 0.02053 & -0.00771 & -0.06417 \\
\hline$\Lambda_{E X P}$ & 0.01221 & 0.01221 & 0.01221 & 0.01221 \\
\hline$\Lambda_{A L L}$ & 0.00018 & 0.00466 & 0.01963 & 0.06450 \\
\hline \multirow[t]{2}{*}{$\Lambda$} & 0.01239 & 0.01687 & 0.03184 & 0.07671 \\
\hline & \multicolumn{4}{|c|}{$\mathrm{CHF} / \mathrm{USD}: p_{m}=3, p_{v}=2$} \\
\hline $\operatorname{ceq}_{R A}$ & 0.05006 & 0.02846 & 0.01550 & 0.00798 \\
\hline $\operatorname{ceq}_{R N}$ & 0.04978 & 0.02120 & -0.01452 & -0.08596 \\
\hline $\operatorname{ceq}_{C H}$ & 0.03354 & 0.00496 & -0.03076 & -0.10221 \\
\hline$\Lambda_{E X P}$ & 0.01624 & 0.01624 & 0.01624 & 0.01624 \\
\hline$\Lambda_{A L L}$ & 0.00028 & 0.00725 & 0.03002 & 0.09394 \\
\hline$\Lambda$ & 0.01652 & 0.02350 & 0.04627 & 0.11018 \\
\hline
\end{tabular}

The parameters $p_{m}$ and $p_{v}$ denote the maximal order of the Taylor expansions used in the estimation.

ceq $_{i}$ denotes the certainty equivalent of strategy $i$ for a trader with constant relative risk aversion denoted in the top of the table. $\operatorname{ceq}_{R A}$ denotes the certainty equivalent based on the optimal trading strategy. $\operatorname{ceq}_{R N}$ denotes the certainty equivalent when the risk averse trader uses the risk neutral optimal portfolio, and ceq $_{C H}$ denotes the certainty equivalent for a risk averse trader following the technical trading rule.

All entries are in per annum terms. 
Table 3: In-sample analysis of certainty equivalent and cost decomosition of technical trading rules. Rule 2: $S=20, L=100$

\begin{tabular}{|c|c|c|c|c|}
\hline & CRRA $=1$ & CRRA $=5$ & CRRA $=10$ & CRRA $=20$ \\
\hline & \multicolumn{4}{|c|}{ DEM/USD: $p_{m}=5, p_{v}=2$} \\
\hline $\operatorname{ceq}_{R A}$ & 0.06572 & 0.04660 & 0.02928 & 0.01484 \\
\hline $\operatorname{ceq}_{R N}$ & 0.06560 & 0.04338 & 0.01560 & -0.03994 \\
\hline $\operatorname{ceq}_{C H}$ & 0.05161 & 0.02939 & 0.00161 & -0.05393 \\
\hline$\Lambda_{E X P}$ & 0.01399 & 0.01399 & 0.01399 & 0.01399 \\
\hline$\Lambda_{A L L}$ & 0.00012 & 0.00322 & 0.01367 & 0.05478 \\
\hline \multirow[t]{2}{*}{$\Lambda$} & 0.01411 & 0.01721 & 0.02766 & 0.06877 \\
\hline & \multicolumn{4}{|c|}{ GBP $/$ USD: $p_{m}=2, p_{v}=4$} \\
\hline$\overline{\operatorname{ceq}}{ }_{R A}$ & 0.02646 & 0.01256 & 0.00641 & 0.00321 \\
\hline $\operatorname{ceq}_{R N}$ & 0.02631 & 0.00798 & -0.01493 & -0.06076 \\
\hline $\operatorname{ceq}_{C H}$ & 0.01291 & -0.00542 & -0.02833 & -0.07416 \\
\hline$\Lambda_{E X P}$ & 0.01340 & 0.01340 & 0.01340 & 0.01340 \\
\hline$\Lambda_{A L L}$ & 0.00015 & 0.00458 & 0.02135 & 0.06396 \\
\hline \multirow[t]{2}{*}{$\Lambda$} & 0.01355 & 0.01798 & 0.03474 & 0.07736 \\
\hline & \multicolumn{4}{|c|}{ JPY /USD: $p_{m}=3, p_{v}=2$} \\
\hline $\operatorname{ceq}_{R A}$ & 0.06492 & 0.04589 & 0.03015 & 0.01585 \\
\hline $\operatorname{ceq}_{R N}$ & 0.06477 & 0.04210 & 0.01376 & -0.04291 \\
\hline $\operatorname{ceq}_{C H}$ & 0.05371 & 0.03104 & 0.00271 & -0.05396 \\
\hline$\Lambda_{E X P}$ & 0.01106 & 0.01106 & 0.01106 & 0.01106 \\
\hline$\Lambda_{A L L}$ & 0.00015 & 0.00379 & 0.01639 & 0.05875 \\
\hline \multirow[t]{2}{*}{$\Lambda$} & 0.01121 & 0.01485 & 0.02745 & 0.06981 \\
\hline & \multicolumn{4}{|c|}{$\mathrm{CHF} / \mathrm{USD}: p_{m}=1, p_{v}=4$} \\
\hline $\operatorname{ceq}_{R A}$ & 0.02565 & 0.00933 & 0.00467 & 0.00234 \\
\hline $\operatorname{ceq}_{R N}$ & 0.02515 & -0.00354 & -0.03941 & -0.11114 \\
\hline $\operatorname{ceq}_{C H}$ & 0.01451 & -0.01418 & -0.05005 & -0.12178 \\
\hline$\Lambda_{E X P}$ & 0.01064 & 0.01064 & 0.01064 & 0.01064 \\
\hline$\Lambda_{A L L}$ & 0.00050 & 0.01287 & 0.04408 & 0.11348 \\
\hline$\Lambda$ & 0.01114 & 0.02351 & 0.05472 & 0.12412 \\
\hline
\end{tabular}

The parameters $p_{m}$ and $p_{v}$ denote the maximal order of the Taylor expansions used in the estimation.

ceq $_{i}$ denotes the certainty equivalent of strategy $i$ for a trader with constant relative risk aversion denoted in the top of the table. $\operatorname{ceq}_{R A}$ denotes the certainty equivalent based on the optimal trading strategy. $\operatorname{ceq}_{R N}$ denotes the certainty equivalent when the risk averse trader uses the risk neutral optimal portfolio, and ceq $_{C H}$ denotes the certainty equivalent for a risk averse trader following the technical trading rule.

All entries are in per annum terms. 
Table 4: In-sample analysis of certainty equivalent and cost decomosition of technical trading rules. Rule 3: $\mathrm{S}=40, \mathrm{~L}=\mathbf{2 0 0}$

\begin{tabular}{|c|c|c|c|c|}
\hline & CRRA $=1$ & CRRA $=5$ & CRRA $=10$ & CRRA $=20$ \\
\hline & \multicolumn{4}{|c|}{ DEM/USD: $p_{m}=3, p_{v}=2$} \\
\hline $\operatorname{ceq}_{R A}$ & 0.04158 & 0.02422 & 0.01289 & 0.00656 \\
\hline $\operatorname{ceq}_{R N}$ & 0.04139 & 0.01938 & -0.00812 & -0.06313 \\
\hline $\operatorname{ceq}_{C H}$ & 0.03208 & 0.01008 & -0.01743 & -0.07244 \\
\hline$\Lambda_{E X P}$ & 0.00931 & 0.00931 & 0.00931 & 0.00931 \\
\hline$\Lambda_{A L L}$ & 0.00020 & 0.00483 & 0.02101 & 0.06969 \\
\hline \multirow[t]{2}{*}{$\Lambda$} & 0.00951 & 0.01414 & 0.03032 & 0.07900 \\
\hline & \multicolumn{4}{|c|}{ GBP $/$ USD: $p_{m}=5, p_{v}=4$} \\
\hline$\overline{\operatorname{ceq}}{ }_{R A}$ & 0.04363 & 0.02821 & 0.01805 & 0.01032 \\
\hline $\operatorname{ceq}_{R N}$ & 0.04357 & 0.02513 & 0.00208 & -0.04401 \\
\hline $\operatorname{ceq}_{C H}$ & 0.02388 & 0.00544 & -0.01743 & -0.06370 \\
\hline$\Lambda_{E X P}$ & 0.01969 & 0.01969 & 0.01969 & 0.01969 \\
\hline$\Lambda_{A L L}$ & 0.00007 & 0.00308 & 0.01596 & 0.05433 \\
\hline \multirow[t]{2}{*}{$\Lambda$} & 0.01975 & 0.02277 & 0.03565 & 0.07402 \\
\hline & \multicolumn{4}{|c|}{ JPY /USD: $p_{m}=3, p_{v}=2$} \\
\hline $\operatorname{ceq}_{R A}$ & 0.04271 & 0.02679 & 0.01627 & 0.00818 \\
\hline $\operatorname{ceq}_{R N}$ & 0.04245 & 0.01960 & -0.00897 & -0.06610 \\
\hline $\operatorname{ceq}_{C H}$ & 0.03641 & 0.01356 & -0.01501 & -0.07214 \\
\hline$\Lambda_{E X P}$ & 0.00604 & 0.00604 & 0.00604 & 0.00604 \\
\hline$\Lambda_{A L L}$ & 0.00026 & 0.00713 & 0.02523 & 0.07428 \\
\hline \multirow[t]{2}{*}{$\Lambda$} & 0.00630 & 0.01324 & 0.03128 & 0.08033 \\
\hline & \multicolumn{4}{|c|}{$\mathrm{CHF} / \mathrm{USD}: p_{m}=3, p_{v}=5$} \\
\hline $\operatorname{ceq}_{R A}$ & 0.04924 & 0.02752 & 0.01498 & 0.00780 \\
\hline $\operatorname{ceq}_{R N}$ & 0.04900 & 0.02053 & -0.01505 & -0.08620 \\
\hline $\operatorname{ceq}_{C H}$ & 0.03489 & 0.00643 & -0.02915 & -0.10031 \\
\hline$\Lambda_{E X P}$ & 0.01411 & 0.01411 & 0.01411 & 0.01411 \\
\hline$\Lambda_{A L L}$ & 0.00024 & 0.00699 & 0.03002 & 0.09401 \\
\hline$\Lambda$ & 0.01435 & 0.02109 & 0.04413 & 0.10811 \\
\hline
\end{tabular}

The parameters $p_{m}$ and $p_{v}$ denote the maximal order of the Taylor expansions used in the estimation.

ceq $_{i}$ denotes the certainty equivalent of strategy $i$ for a trader with constant relative risk aversion denoted in the top of the table. $\operatorname{ceq}_{R A}$ denotes the certainty equivalent based on the optimal trading strategy. $\operatorname{ceq}_{R N}$ denotes the certainty equivalent when the risk averse trader uses the risk neutral optimal portfolio, and ceq $_{C H}$ denotes the certainty equivalent for a risk averse trader following the technical trading rule.

All entries are in per annum terms. 
Table 5: Dynamic estimation of certainty equivalent and cost decomosition of technical trading rules. Rule 1: $\mathrm{S}=10, \mathrm{~L}=50$

\begin{tabular}{|c|c|c|c|c|}
\hline & CRRA $=1$ & CRRA $=5$ & CRRA $=10$ & CRRA $=20$ \\
\hline & \multicolumn{4}{|c|}{$\mathrm{DEM} / \mathrm{USD}: p_{m}=3, p_{v}=2$} \\
\hline $\operatorname{ceq}_{R A}$ & 0.08300 & 0.06459 & 0.04627 & 0.02673 \\
\hline $\operatorname{ceq}_{R N}$ & 0.08290 & 0.06216 & 0.03625 & -0.01559 \\
\hline $\operatorname{ceq}_{C H}$ & 0.06544 & 0.04471 & 0.01879 & -0.03304 \\
\hline$\Lambda_{E X P}$ & 0.01746 & 0.01746 & 0.01746 & 0.01746 \\
\hline$\Lambda_{A L L}$ & 0.00010 & 0.00242 & 0.01003 & 0.04232 \\
\hline \multirow[t]{2}{*}{$\Lambda$} & 0.01756 & 0.01988 & 0.02748 & 0.05977 \\
\hline & \multicolumn{4}{|c|}{ GBP/USD: $p_{m}=4, p_{v}=6$} \\
\hline $\operatorname{ceq}_{R A}$ & 0.06443 & 0.04915 & 0.03556 & 0.02239 \\
\hline $\operatorname{ceq}_{R N}$ & 0.06435 & 0.04688 & 0.02504 & -0.01863 \\
\hline $\operatorname{ceq}_{C H}$ & 0.03843 & 0.02096 & -0.00087 & -0.04455 \\
\hline$\Lambda_{E X P}$ & 0.02592 & 0.02592 & 0.02592 & 0.02592 \\
\hline$\Lambda_{A L L}$ & 0.00009 & 0.00227 & 0.01052 & 0.04102 \\
\hline \multirow[t]{2}{*}{$\Lambda$} & 0.02600 & 0.02818 & 0.03643 & 0.06694 \\
\hline & \multicolumn{4}{|c|}{ JPY/USD: $p_{m}=3, p_{v}=4$} \\
\hline $\operatorname{ceq}_{R A}$ & 0.07545 & 0.05784 & 0.04172 & 0.02356 \\
\hline $\operatorname{ceq}_{R N}$ & 0.07534 & 0.05511 & 0.02982 & -0.02076 \\
\hline $\operatorname{ceq}_{C H}$ & 0.06344 & 0.04321 & 0.01792 & -0.03266 \\
\hline$\Lambda_{E X P}$ & 0.01190 & 0.01190 & 0.01190 & 0.01190 \\
\hline$\Lambda_{A L L}$ & 0.00011 & 0.00273 & 0.01190 & 0.04432 \\
\hline \multirow[t]{2}{*}{$\Lambda$} & 0.01201 & 0.01463 & 0.02381 & 0.05622 \\
\hline & \multicolumn{4}{|c|}{$\mathrm{CHF} / \mathrm{USD}: p_{m}=3, p_{v}=2$} \\
\hline $\operatorname{ceq}_{R A}$ & 0.09748 & 0.07226 & 0.05002 & 0.02972 \\
\hline $\operatorname{ceq}_{R N}$ & 0.09732 & 0.06809 & 0.03156 & -0.04151 \\
\hline $\operatorname{ceq}_{C H}$ & 0.05656 & 0.02733 & -0.00921 & -0.08227 \\
\hline$\Lambda_{E X P}$ & 0.04076 & 0.04076 & 0.04076 & 0.04076 \\
\hline$\Lambda_{A L L}$ & 0.00016 & 0.00417 & 0.01847 & 0.07123 \\
\hline$\Lambda$ & 0.04092 & 0.04493 & 0.05923 & 0.11199 \\
\hline
\end{tabular}

The parameters $p_{m}$ and $p_{v}$ denote the maximal order of the Taylor expansions used in the estimation.

ceq $_{i}$ denotes the certainty equivalent of strategy $i$ for a trader with constant relative risk aversion denoted in the top of the table. $\operatorname{ceq}_{R A}$ denotes the certainty equivalent based on the optimal trading strategy. $\operatorname{ceq}_{R N}$ denotes the certainty equivalent when the risk averse trader uses the risk neutral optimal portfolio, and ceq $_{C H}$ denotes the certainty equivalent for a risk averse trader following the technical trading rule.

All entries are in per annum terms. 
Table 6: Dynamic estimation of certainty equivalent and cost decomosition of technical trading rules. Rule 2: $S=20, L=100$

\begin{tabular}{|c|c|c|c|c|}
\hline & CRRA $=1$ & CRRA $=5$ & CRRA $=10$ & CRRA $=20$ \\
\hline & \multicolumn{4}{|c|}{$\mathrm{DEM} / \mathrm{USD}: p_{m}=5, p_{v}=2$} \\
\hline $\operatorname{ceq}_{R A}$ & 0.09484 & 0.07647 & 0.05796 & 0.03584 \\
\hline $\operatorname{ceq}_{R N}$ & 0.09475 & 0.07426 & 0.04865 & -0.00258 \\
\hline $\operatorname{ceq}_{C H}$ & 0.08419 & 0.06370 & 0.03809 & -0.01314 \\
\hline$\Lambda_{E X P}$ & 0.01056 & 0.01056 & 0.01056 & 0.01056 \\
\hline$\Lambda_{A L L}$ & 0.00008 & 0.00221 & 0.00931 & 0.03842 \\
\hline \multirow[t]{2}{*}{$\Lambda$} & 0.01064 & 0.01276 & 0.01987 & 0.04898 \\
\hline & \multicolumn{4}{|c|}{ GBP/USD: $p_{m}=2, p_{v}=4$} \\
\hline $\operatorname{ceq}_{R A}$ & 0.05701 & 0.04218 & 0.03013 & 0.01864 \\
\hline $\operatorname{ceq}_{R N}$ & 0.05692 & 0.03965 & 0.01806 & -0.02512 \\
\hline $\operatorname{ceq}_{C H}$ & 0.02548 & 0.00820 & -0.01339 & -0.05657 \\
\hline$\Lambda_{E X P}$ & 0.03144 & 0.03144 & 0.03144 & 0.03144 \\
\hline$\Lambda_{A L L}$ & 0.00009 & 0.00253 & 0.01207 & 0.04376 \\
\hline \multirow[t]{2}{*}{$\Lambda$} & 0.03153 & 0.03397 & 0.04352 & 0.07520 \\
\hline & \multicolumn{4}{|c|}{ JPY/USD: $p_{m}=3, p_{v}=2$} \\
\hline $\operatorname{ceq}_{R A}$ & 0.07296 & 0.05601 & 0.04130 & 0.02475 \\
\hline $\operatorname{ceq}_{R N}$ & 0.07284 & 0.05279 & 0.02772 & -0.02243 \\
\hline $\operatorname{ceq}_{C H}$ & 0.05461 & 0.03456 & 0.00948 & -0.04066 \\
\hline$\Lambda_{E X P}$ & 0.01823 & 0.01823 & 0.01823 & 0.01823 \\
\hline$\Lambda_{A L L}$ & 0.00012 & 0.00323 & 0.01358 & 0.04718 \\
\hline \multirow[t]{2}{*}{$\Lambda$} & 0.01835 & 0.02146 & 0.03181 & 0.06541 \\
\hline & \multicolumn{4}{|c|}{$\mathrm{CHF} / \mathrm{USD}: p_{m}=1, p_{v}=4$} \\
\hline $\operatorname{ceq}_{R A}$ & 0.04483 & 0.02356 & 0.01290 & 0.00651 \\
\hline $\operatorname{ceq}_{R N}$ & 0.04448 & 0.01500 & -0.02185 & -0.09555 \\
\hline $\operatorname{ceq}_{C H}$ & 0.02164 & -0.00785 & -0.04470 & -0.11840 \\
\hline$\Lambda_{E X P}$ & 0.02284 & 0.02284 & 0.02284 & 0.02284 \\
\hline$\Lambda_{A L L}$ & 0.00035 & 0.00856 & 0.03475 & 0.10206 \\
\hline$\Lambda$ & 0.02319 & 0.03141 & 0.05759 & 0.12490 \\
\hline
\end{tabular}

The parameters $p_{m}$ and $p_{v}$ denote the maximal order of the Taylor expansions used in the estimation.

ceq $_{i}$ denotes the certainty equivalent of strategy $i$ for a trader with constant relative risk aversion denoted in the top of the table. ceq ${ }_{R A}$ denotes the certainty equivalent based on the optimal trading strategy. ceq $R N$ denotes the certainty equivalent when the risk averse trader uses the risk neutral optimal portfolio, and ceq $_{C H}$ denotes the certainty equivalent for a risk averse trader following the technical trading rule.

All entries are in per annum terms. 
Table 7: Dynamic estmation of certainty equivalent and cost decomosition of technical trading rules. Rule 3: $\mathrm{S}=40, \mathrm{~L}=200$

\begin{tabular}{|c|c|c|c|c|}
\hline & CRRA $=1$ & CRRA $=5$ & CRRA $=10$ & CRRA $=20$ \\
\hline & \multicolumn{4}{|c|}{ DEM/USD: $p_{m}=3, p_{v}=2$} \\
\hline $\operatorname{ceq}_{R A}$ & 0.05654 & 0.03985 & 0.02612 & 0.01486 \\
\hline $\operatorname{ceq}_{R N}$ & 0.05642 & 0.03660 & 0.01183 & -0.03770 \\
\hline $\operatorname{ceq}_{C H}$ & 0.04682 & 0.02701 & 0.00224 & -0.04730 \\
\hline$\Lambda_{E X P}$ & 0.00960 & 0.00960 & 0.00960 & 0.00960 \\
\hline$\Lambda_{A L L}$ & 0.00012 & 0.00325 & 0.01428 & 0.05256 \\
\hline \multirow[t]{2}{*}{$\Lambda$} & 0.00972 & 0.01285 & 0.02388 & 0.06216 \\
\hline & \multicolumn{4}{|c|}{$\mathrm{GBP} / \mathrm{USD}: p_{m}=5, p_{v}=4$} \\
\hline $\operatorname{ceq}_{R A}$ & 0.08010 & 0.06466 & 0.04995 & 0.03381 \\
\hline $\operatorname{ceq}_{R N}$ & 0.08004 & 0.06309 & 0.04190 & -0.00048 \\
\hline $\operatorname{ceq}_{C H}$ & 0.04229 & 0.02534 & 0.00415 & -0.03823 \\
\hline$\Lambda_{E X P}$ & 0.03775 & 0.03775 & 0.03775 & 0.03775 \\
\hline$\Lambda_{A L L}$ & 0.00006 & 0.00157 & 0.00805 & 0.03428 \\
\hline \multirow[t]{2}{*}{$\Lambda$} & 0.03781 & 0.03932 & 0.04580 & 0.07203 \\
\hline & \multicolumn{4}{|c|}{ JPY /USD: $p_{m}=3, p_{v}=2$} \\
\hline $\operatorname{ceq}_{R A}$ & 0.05941 & 0.04480 & 0.03315 & 0.02030 \\
\hline $\operatorname{ceq}_{R N}$ & 0.05919 & 0.03908 & 0.01394 & -0.03634 \\
\hline $\operatorname{ceq}_{C H}$ & 0.03672 & 0.01661 & -0.00853 & -0.05880 \\
\hline$\Lambda_{E X P}$ & 0.02247 & 0.02247 & 0.02247 & 0.02247 \\
\hline$\Lambda_{A L L}$ & 0.00021 & 0.00572 & 0.01920 & 0.05663 \\
\hline \multirow[t]{2}{*}{$\Lambda$} & 0.02269 & 0.02819 & 0.04167 & 0.07910 \\
\hline & \multicolumn{4}{|c|}{$\mathrm{CHF} / \mathrm{USD}: p_{m}=3, p_{v}=5$} \\
\hline $\operatorname{ceq}_{R A}$ & 0.07474 & 0.05126 & 0.03286 & 0.01865 \\
\hline $\operatorname{ceq}_{R N}$ & 0.07454 & 0.04589 & 0.01007 & -0.06155 \\
\hline $\operatorname{ceq}_{C H}$ & 0.05611 & 0.00275 & -0.00836 & -0.07998 \\
\hline$\Lambda_{E X P}$ & 0.01843 & 0.01843 & 0.01843 & 0.01843 \\
\hline$\Lambda_{A L L}$ & 0.00021 & 0.00538 & 0.02279 & 0.08020 \\
\hline$\Lambda$ & 0.01864 & 0.02381 & 0.04122 & 0.09863 \\
\hline
\end{tabular}

The parameters $p_{m}$ and $p_{v}$ denote the maximal order of the Taylor expansions used in the estimation.

ceq $_{i}$ denotes the certainty equivalent of strategy $i$ for a trader with constant relative risk aversion denoted in the top of the table. ceq ${ }_{R A}$ denotes the certainty equivalent based on the optimal trading strategy. ceq $R N$ denotes the certainty equivalent when the risk averse trader uses the risk neutral optimal portfolio, and ceq $_{C H}$ denotes the certainty equivalent for a risk averse trader following the technical trading rule.

All entries are in per annum terms. 
Table 8: Out-of-sample certainty equivalent and cost decomposition of technical trading rules. Rule 1: $\mathrm{S}=10, \mathrm{~L}=50$

\begin{tabular}{|c|c|c|c|c|}
\hline & CRRA $=1$ & CRRA $=5$ & CRRA $=10$ & $\mathrm{CRRA}=20$ \\
\hline & \multicolumn{4}{|c|}{$\mathrm{DEM} / \mathrm{USD}: p_{m}=3, p_{v}=2$} \\
\hline $\operatorname{ceq}_{R A}$ & 0.06515 & 0.04079 & 0.02045 & 0.01149 \\
\hline $\operatorname{ceq}_{R N}$ & 0.06376 & 0.04090 & 0.01233 & -0.04482 \\
\hline $\operatorname{ceq}_{C H}$ & 0.04125 & 0.01837 & -0.01023 & -0.06743 \\
\hline$\Lambda_{E X P}$ & 0.02250 & 0.02250 & 0.02250 & 0.02250 \\
\hline$\Lambda_{A L L}$ & 0.00140 & -0.00008 & 0.00819 & 0.05642 \\
\hline \multirow[t]{2}{*}{$\Lambda$} & 0.02390 & 0.02242 & 0.03068 & 0.07892 \\
\hline & \multicolumn{4}{|c|}{ GBP/USD: $p_{m}=4, p_{v}=6$} \\
\hline$\overline{\operatorname{ceq}_{R A}}$ & 0.03140 & 0.02170 & 0.01410 & 0.01082 \\
\hline $\operatorname{ceq}_{R N}$ & 0.02802 & 0.00856 & -0.01577 & -0.06442 \\
\hline $\operatorname{ceq}_{C H}$ & 0.02786 & 0.00835 & -0.01605 & -0.06485 \\
\hline$\Lambda_{E X P}$ & 0.00014 & 0.00014 & 0.00014 & 0.00014 \\
\hline$\Lambda_{A L L}$ & 0.00339 & 0.01321 & 0.03001 & 0.07552 \\
\hline \multirow[t]{2}{*}{$\Lambda$} & 0.00354 & 0.01336 & 0.03016 & 0.07567 \\
\hline & \multicolumn{4}{|c|}{ JPY /USD: $p_{m}=3, p_{v}=4$} \\
\hline $\operatorname{ceq}_{R A}$ & 0.07707 & 0.05626 & 0.03973 & 0.02183 \\
\hline $\operatorname{ceq}_{R N}$ & 0.07669 & 0.05217 & 0.02153 & -0.03976 \\
\hline $\operatorname{ceq}_{C H}$ & 0.05449 & 0.03000 & -0.00618 & -0.06185 \\
\hline$\Lambda_{E X P}$ & 0.02221 & 0.02221 & 0.02221 & 0.02221 \\
\hline$\Lambda_{A L L}$ & 0.00375 & 0.00406 & 0.01814 & 0.06148 \\
\hline \multirow[t]{2}{*}{$\Lambda$} & 0.02258 & 0.02627 & 0.04034 & 0.08368 \\
\hline & \multicolumn{4}{|c|}{$\mathrm{CHF} / \mathrm{USD}: p_{m}=3, p_{v}=4$} \\
\hline $\operatorname{ceq}_{R A}$ & 0.07492 & 0.04566 & 0.02447 & 0.01538 \\
\hline $\operatorname{ceq}_{R N}$ & 0.06883 & 0.03938 & 0.00256 & -0.07107 \\
\hline $\operatorname{ceq}_{C H}$ & 0.05300 & 0.00236 & -0.01322 & -0.08679 \\
\hline$\Lambda_{E X P}$ & 0.01584 & 0.01584 & 0.01584 & 0.01584 \\
\hline$\Lambda_{A L L}$ & 0.00609 & 0.00625 & 0.02185 & 0.08633 \\
\hline$\Lambda$ & 0.02193 & 0.02209 & 0.03769 & 0.10217 \\
\hline
\end{tabular}

The parameters $p_{m}$ and $p_{v}$ denote the maximal order of the Taylor expansions used in the estimation.

ceq $_{i}$ denotes the certainty equivalent of strategy $i$ for a trader with constant relative risk aversion denoted in the top of the table. $\operatorname{ceq}_{R A}$ denotes the certainty equivalent based on the optimal trading strategy. $\operatorname{ceq}_{R N}$ denotes the certainty equivalent when the risk averse trader uses the risk neutral optimal portfolio, and ceq $_{C H}$ denotes the certainty equivalent for a risk averse trader following the technical trading rule.

All entries are in per annum terms. 
Table 9: Out-of-sample certainty equivalent and cost decomposition of technical trading rules. Rule 2: $\mathrm{S}=\mathbf{2 0}, \mathrm{L}=100$

\begin{tabular}{|c|c|c|c|c|}
\hline & CRRA $=1$ & CRRA $=5$ & CRRA $=10$ & $\mathrm{CRRA}=20$ \\
\hline & \multicolumn{4}{|c|}{$\mathrm{DEM} / \mathrm{USD}: p_{m}=5, p_{v}=2$} \\
\hline $\operatorname{ceq}_{R A}$ & 0.06192 & 0.04303 & 0.02490 & 0.01362 \\
\hline $\operatorname{ceq}_{R N}$ & 0.06118 & 0.03826 & 0.00962 & -0.04766 \\
\hline $\operatorname{ceq}_{C H}$ & 0.03582 & 0.01288 & -0.01579 & -0.07313 \\
\hline$\Lambda_{E X P}$ & 0.02536 & 0.02536 & 0.02536 & 0.02536 \\
\hline$\Lambda_{A L L}$ & 0.00075 & 0.00479 & 0.01533 & 0.06140 \\
\hline \multirow[t]{2}{*}{$\Lambda$} & 0.02611 & 0.03015 & 0.04069 & 0.08675 \\
\hline & \multicolumn{4}{|c|}{ GBP/USD: $p_{m}=2, p_{v}=4$} \\
\hline$\overline{\operatorname{ceq}_{R A}}$ & 0.01417 & 0.00482 & 0.00072 & -0.00182 \\
\hline $\operatorname{ceq}_{R N}$ & 0.01267 & -0.00689 & -0.03133 & -0.08021 \\
\hline $\operatorname{ceq}_{C H}$ & 0.03418 & 0.01467 & -0.00971 & -0.05847 \\
\hline$\Lambda_{E X P}$ & -0.02146 & -0.02150 & -0.02150 & -0.02150 \\
\hline$\Lambda_{A L L}$ & 0.00149 & 0.01165 & 0.03192 & 0.07815 \\
\hline \multirow[t]{2}{*}{$\Lambda$} & -0.02001 & -0.00985 & 0.01043 & 0.05665 \\
\hline & \multicolumn{4}{|c|}{ JPY /USD: $p_{m}=3, p_{v}=2$} \\
\hline $\operatorname{ceq}_{R A}$ & 0.06967 & 0.06002 & 0.03879 & 0.02000 \\
\hline $\operatorname{ceq}_{R N}$ & 0.06601 & 0.04151 & 0.01087 & -0.05039 \\
\hline $\operatorname{ceq}_{C H}$ & 0.05228 & 0.02779 & -0.00283 & -0.06406 \\
\hline$\Lambda_{E X P}$ & 0.01373 & 0.01373 & 0.01373 & 0.01373 \\
\hline$\Lambda_{A L L}$ & 0.00365 & 0.01850 & 0.02788 & 0.07032 \\
\hline \multirow[t]{2}{*}{$\Lambda$} & 0.01739 & 0.03223 & 0.04162 & 0.08406 \\
\hline & \multicolumn{4}{|c|}{$\mathrm{CHF} / \mathrm{USD}: p_{m}=1, p_{v}=4$} \\
\hline $\operatorname{ceq}_{R A}$ & 0.02086 & 0.01335 & 0.00987 & 0.00540 \\
\hline $\operatorname{ceq}_{R N}$ & 0.01726 & -0.01194 & -0.04843 & -0.12141 \\
\hline $\operatorname{ceq}_{C H}$ & 0.03209 & 0.00290 & -0.03359 & -0.10656 \\
\hline$\Lambda_{E X P}$ & -0.01483 & -0.01483 & -0.01483 & -0.01483 \\
\hline$\Lambda_{A L L}$ & 0.00361 & 0.02528 & 0.05829 & 0.12679 \\
\hline$\Lambda$ & -0.01122 & 0.01046 & 0.04346 & 0.11196 \\
\hline
\end{tabular}

The parameters $p_{m}$ and $p_{v}$ denote the maximal order of the Taylor expansions used in the estimation.

$\operatorname{ceq}_{i}$ denotes the certainty equivalent of strategy $i$ for a trader with constant relative risk aversion denoted in the top of the table. $\operatorname{ceq}_{R A}$ denotes the certainty equivalent based on the optimal trading strategy. $\operatorname{ceq}_{R N}$ denotes the certainty equivalent when the risk averse trader uses the risk neutral optimal portfolio, and ceq $_{C H}$ denotes the certainty equivalent for a risk averse trader following the technical trading rule.

All entries are in per annum terms. 
Table 10: Out of sample certainty equivalent and cost decomposition of technical trading rules. Rule 3: $\mathrm{S}=40, \mathrm{~L}=\mathbf{2 0 0}$

\begin{tabular}{|c|c|c|c|c|}
\hline & CRRA $=1$ & CRRA $=5$ & CRRA $=10$ & CRRA $=20$ \\
\hline & \multicolumn{4}{|c|}{$\mathrm{DEM} / \mathrm{USD}: p_{m}=3, p_{v}=2$} \\
\hline $\operatorname{ceq}_{R A}$ & 0.05256 & 0.02888 & 0.01988 & 0.00950 \\
\hline $\operatorname{ceq}_{R N}$ & 0.05194 & 0.02910 & 0.00054 & -0.05657 \\
\hline $\operatorname{ceq}_{C H}$ & 0.01637 & -0.00649 & -0.03506 & -0.09221 \\
\hline$\Lambda_{E X P}$ & 0.03557 & 0.03557 & 0.03557 & 0.03557 \\
\hline$\Lambda_{A L L}$ & 0.00062 & -0.00020 & 0.01937 & 0.06614 \\
\hline \multirow[t]{2}{*}{$\Lambda$} & 0.03619 & 0.03537 & 0.05494 & 0.10171 \\
\hline & \multicolumn{4}{|c|}{ GBP $/$ USD: $p_{m}=5, p_{v}=4$} \\
\hline$\overline{\operatorname{ceq}}{ }_{R A}$ & 0.03671 & 0.01919 & 0.01125 & 0.00848 \\
\hline $\operatorname{ceq}_{R N}$ & 0.03565 & 0.01605 & -0.00845 & -0.05745 \\
\hline $\operatorname{ceq}_{C H}$ & 0.03055 & 0.01085 & -0.01378 & -0.06304 \\
\hline$\Lambda_{E X P}$ & 0.00507 & 0.00507 & 0.00507 & 0.00507 \\
\hline$\Lambda_{A L L}$ & 0.00108 & 0.00327 & 0.01996 & 0.06645 \\
\hline \multirow[t]{2}{*}{$\Lambda$} & 0.00616 & 0.00834 & 0.02503 & 0.07152 \\
\hline & \multicolumn{4}{|c|}{ JPY /USD: $p_{m}=3, p_{v}=2$} \\
\hline $\operatorname{ceq}_{R A}$ & 0.03977 & 0.02901 & 0.01916 & 0.01249 \\
\hline $\operatorname{ceq}_{R N}$ & 0.03788 & 0.01334 & -0.01734 & -0.07870 \\
\hline $\operatorname{ceq}_{C H}$ & 0.02292 & -0.00152 & -0.03207 & -0.09318 \\
\hline$\Lambda_{E X P}$ & 0.01498 & 0.01498 & 0.01498 & 0.01498 \\
\hline$\Lambda_{A L L}$ & 0.00187 & 0.01555 & 0.03625 & 0.09069 \\
\hline \multirow[t]{2}{*}{$\Lambda$} & 0.01685 & 0.03053 & 0.05123 & 0.10567 \\
\hline & \multicolumn{4}{|c|}{$\mathrm{CHF} / \mathrm{USD}: p_{m}=3, p_{v}=5$} \\
\hline $\operatorname{ceq}_{R A}$ & 0.04816 & 0.03527 & 0.02827 & 0.01596 \\
\hline $\operatorname{ceq}_{R N}$ & 0.04003 & 0.01074 & -0.02588 & -0.09910 \\
\hline $\operatorname{ceq}_{C H}$ & 0.03261 & 0.00335 & -0.03322 & -0.10637 \\
\hline$\Lambda_{E X P}$ & 0.00742 & 0.00742 & 0.00742 & 0.00742 \\
\hline$\Lambda_{A L L}$ & 0.00812 & 0.02449 & 0.05407 & 0.11490 \\
\hline$\Lambda$ & 0.01555 & 0.03192 & 0.06149 & 0.12232 \\
\hline
\end{tabular}

The parameters $p_{m}$ and $p_{v}$ denote the maximal order of the Taylor expansions used in the estimation.

ceq $_{i}$ denotes the certainty equivalent of strategy $i$ for a trader with constant relative risk aversion denoted in the top of the table. $\operatorname{ceq}_{R A}$ denotes the certainty equivalent based on the optimal trading strategy. $\operatorname{ceq}_{R N}$ denotes the certainty equivalent when the risk averse trader uses the risk neutral optimal portfolio, and ceq $_{C H}$ denotes the certainty equivalent for a risk averse trader following the technical trading rule.

All entries are in per annum terms. 


\section{Publications in the Report Series Research* in Management}

ERIM Research Program: "Finance and Accounting"

2003

COMMENT, Risk Aversion and Skewness Preference

Thierry Post and Pim van Vliet

ERS-2003-009-F\&A

http://hdl.handle.net/1765/319

International Portfolio Choice: A Spanning Approach

Ben Tims, Ronald Mahieu

ERS-2003-011-F\&A

http://hdl.handle.net/1765/276

Portfolio Return Characteristics Of Different Industries

Igor Pouchkarev, Jaap Spronk, Pim van Vliet

ERS-2003-014-F\&A

http://hdl.handle.net/1765/272

Asset prices and omitted moments

A stochastic dominance analysis of market efficiency

Thierry Post

ERS-2003-017-F\&A

http://hdl.handle.net/1765/430

A Multidimensional Framework for Financial-Economic Decisions

Winfried Hallerbach \& Jaap Spronk

ERS-2003-021-F\&A

http://hdl.handle.net/1765/321

A Range-Based Multivariate Model for Exchange Rate Volatility

Ben Tims, Ronald Mahieu

ERS-2003-022-F\&A

http://hdl.handle.net/1765/282

Macro factors and the Term Structure of Interest Rates

Hans Dewachter and Marco Lyrio

ERS-2003-037-F\&A

http://hdl.handle.net/1765/324

The effects of decision flexibility in the hierarchical investment decision process

Winfried Hallerbach, Haikun Ning, Jaap Spronk

ERS-2003-047-F\&A

http://hdl.handle.net/1765/426

* A complete overview of the ERIM Report Series Research in Management: http://www.erim.eur.nl

ERIM Research Programs:

LIS Business Processes, Logistics and Information Systems

ORG Organizing for Performance

MKT Marketing

F\&A Finance and Accounting

STR Strategy and Entrepreneurship 
Takeover defenses and IPO firm value in the Netherlands

Peter Roosenboom, Tjalling van der Goot

ERS-2003-049-F\&A

http://hdl.handle.net/1765/433

The Cost of Technical Trading Rules in the Forex Market: A Utility-based Evaluation

Hans Dewachter and Marco Lyrio

ERS-2003-052-F\&A 